\title{
Review of fecal microbiota transplantation in autistic children and feasible techniques for fecal microbiota transplant delivery
}

\author{
Darina Malygina $^{1 *}$, Alexander Volkov ${ }^{1}$, Olga Zhukova $^{1}$, Olga Vorobyova $^{1}$, Dmitry Panteleev ${ }^{1}$, Daria Zykova ${ }^{1}$, \\ Anna Blagonravova ${ }^{2}$ \\ ${ }^{1}$ Department of Pharmaceutical Chemistry, Federal State Budgetary Educational Institution of Higher Education, Privolzhsky Research Medical University, \\ Ministry of Health of the Russian Federation, Nizhny Novgorod, Russia. \\ ${ }^{2}$ Department of Epidemiology, Microbiology and Evidence-Based Medicine, Federal State Budgetary Educational Institution of Higher Education, Privolzhsky \\ Research Medical University, Ministry of Health of the Russian Federation, Nizhny Novgorod, Russia.
}

\section{ARTICLE INFO \\ Received on: 26/04/2021 \\ Accepted on: 25/10/2021 \\ Available Online: 05/02/2022}

Key words:

Fecal microbiota

transplantation, autism

spectrum disorders, capsules

\begin{abstract}
The review considers the implementation of fecal microbiota transplantation (FMT) to treat several kinds of diseases such as gastrointestinal disorders, diabetes mellitus, metabolic syndrome, and others. The use of FMT in the treatment of neurological disorders such as autism spectrum disorders in children is considered in more detail. We compared the techniques used to deliver FMTs, such as capsules, enemas, introduction through upper gastrointestinal tract, and colonoscopy. This article demonstrates various approaches to the preparation of capsules with lyophilisate of FMTs, such as suspending, microencapsulation, and use of capsule-in-a-capsule technology. These techniques are designed to protect the fecal microbiota microorganisms from the acidic $\mathrm{pH}$ of the gastric juice.
\end{abstract}

\section{INTRODUCTION}

Fecal microbiota transplantation (FMT) is a transplantation process of intestinal bacteria and bacteriophages contained in the feces of healthy individuals to the recipients suffering from gut microbiota imbalance.

The technique can be applied to treat gastrointestinal (GI) diseases, primarily recurrent Clostridium difficile infection (CDI) (Baunwall et al., 2020; Cammarota et al., 2015; Hota et al., 2017; Hvas et al., 2017, 2019; Jiang et al., 2017, 2018; Kao, 2014; Kao et al., 2017; Lynch et al., 2019; Nood et al., 2013; Staley et al., 2018, 2019; Youngster et al., 2014a, 2014b), as well as GI diseases such as colitis (nonspecific ulcerative colitis) (Adler et al., 2019; Angelberger et al., 2013; Cold et al., 2019; Landy et al.,

\footnotetext{
*Corresponding Author

Darina Malygina, Department of Pharmaceutical Chemistry, Federal State Budgetary Educational Institution of Higher Education, Privolzhsky Research Medical University, Ministry of Health of the Russian Federation, Nizhny Novgorod, Russia.E-mail: mds73@yandex.ru
}

2013; Moayyedi et al., 2015; Paramsothy et al., 2017; Shi et al., 2016; Sood et al., 2019), Crohn's disease (Bak et al., 2017; Cui et al., 2015, 2016; Kao et al., 2014), chronic constipations, chronic diarrheas, chronic intestinal infections (chronic shigellosis, chronic salmonellosis, yersiniosis, campylobacteriosis, etc.), irritable bowel syndrome, and others (El-Salhy et al., 2020). Recently, FMT is being widely used in endocrine and metabolic disorders (obesity) (Zhang et al., 2019), diabetes mellitus (Wang et al., 2020), and metabolic syndrome (Groot et al., 2017; Zhang et al., 2019), hepatic diseases (hepatic encephalopathy) (Sidhu et al., 2017), neurological disorders (Parkinson's disease, Alzheimer's disease, multiple sclerosis, epilepsy, and stroke), and psychiatric disorders [autism spectrum disorders (ASD), bipolar disorder, depressive syndrome, schizophrenia, etc.] (Vendrik et al., 2020; Xu et al., 2021).

Table 1 shows the most common delivery techniques for fecal microbiota, such as lower GI endoscopy, introduction through upper gastrointestinal tract, and use of enemas or capsules. Lower GI endoscopy includes colonoscopy, enteroscopy, and sigmoidoscopy. Introduction through upper GIT is carried out using the nasojejunal or gastric tube and other medical devices. 
Table 1. Implementation of FMT in the management of GI diseases and nervous disorders.

\begin{tabular}{|c|c|c|c|}
\hline & $\operatorname{logy}$ & Delivery techniques & Reference \\
\hline \multirow{9}{*}{ GI diseases } & \multirow{4}{*}{$\begin{array}{c}\text { Recurrent } \\
\text { Clostridium } \\
\text { difficile infection }\end{array}$} & Capsules & $\begin{array}{c}\text { Kao, 2014; Youngster et al., 2017; Kao et al., 2017; Staley et al., } \\
\text { 2018; Jiang et al., } 2018 \text { Staley et al., 2019; }\end{array}$ \\
\hline & & Lower GI endoscopy & $\begin{array}{l}\text { Kao, 2014; Youngster et al., 2014; Cammarota et al., 2015; Kao et } \\
\text { al., 2017; Hvas et al., 2017; Hvas et al., } 2019 \text { Lynch et al., 2019; }\end{array}$ \\
\hline & & Enema & Jiang et al., 2018; Hota et al., 2017 \\
\hline & & $\begin{array}{l}\text { Introduction through upper gastrointestinal tract } \\
\text { (nasojejunal or gastric tube, etc.) }\end{array}$ & Youngster et al., 2014; Hvas et al., 2017; Nood et al., 2013 \\
\hline & \multirow{4}{*}{$\begin{array}{l}\text { Nonspecific } \\
\text { ulcerative colitis }\end{array}$} & Capsules & Cold et al., 2019; Adler et al., 2019 \\
\hline & & Colonoscopy & Sood et al., 2019 \\
\hline & & Enema & $\begin{array}{l}\text { Moayyedi et al., 2015; Paramsothy et al., 2017; Angelberger et al., } \\
2013\end{array}$ \\
\hline & & $\begin{array}{l}\text { Introduction through upper gastrointestinal tract } \\
\text { (nasojejunal or gastric tube, etc.) }\end{array}$ & Angelberger et al., 2013; Landy et al., 2013 \\
\hline & Crohn`s disease & $\begin{array}{l}\text { Introduction through upper gastrointestinal tract } \\
\text { (nasojejunal or gastric tube, etc.) }\end{array}$ & Bak et al., 2017; Cui et al., 2015 \\
\hline \multirow{8}{*}{$\begin{array}{l}\text { Neurological } \\
\text { disorders }\end{array}$} & \multirow{4}{*}{$\begin{array}{l}\text { Parkinson`s } \\
\text { disease }\end{array}$} & Capsules & DuPont, 2017 \\
\hline & & Colonoscopy & Xue et al., 2020; Huang et al., 2019 \\
\hline & & $\begin{array}{l}\text { Introduction through upper gastrointestinal tract } \\
\text { (nasojejunal or gastric tube, etc.) }\end{array}$ & Xue et al., 2020 \\
\hline & & Transendoscopic enteral tube & Huang et al., 2019 \\
\hline & \multirow{2}{*}{$\begin{array}{l}\text { Alzheimer`s } \\
\text { disease }\end{array}$} & Intragastric introduction (mice) & Sun et al., 2019 \\
\hline & & Colonoscopy & Hazan et al., 2020 \\
\hline & \multirow{2}{*}{ Multiple sclerosis } & Fecal microbiota infusion & Borody et al., 2011 \\
\hline & & Enema & Kremenchutzky, 2017 \\
\hline \multirow{2}{*}{$\begin{array}{l}\text { Psychiatric } \\
\text { disorders }\end{array}$} & Bipolar disorder & Colonoscopy & Taylor, 2017 \\
\hline & $\begin{array}{l}\text { Depressive } \\
\text { syndrome }\end{array}$ & $\begin{array}{l}\text { Introduction through upper gastrointestinal tract } \\
\text { (gastroscopy) }\end{array}$ & Cai et al., 2019 \\
\hline
\end{tabular}

Capsules and enemas have been shown to be more easy to use for patients, while FMTs introduced by lower GI endoscopy and through upper GIT require special equipment and trained staff; however, they can be more effective and have fewer potential side effects.

This review examines works that have been consequential in the field of FMT use in the treatment of ASD in children, including clinical trials and literature on various methods of FMT delivery. The main objectives of this review are as follows: (i) analysis of FMT use in ASD treatment in children; (ii) comparison of different FMT delivery methods to the intestine; and (iii) offering various methods of protecting fecal microbiota microorganisms in capsules based on literature data.

\section{FMT IN CHILDREN WITH ASD}

Recently, FMT is being extensively explored to correct ASD (Adams et al., 2019), including those in children (Kang et al., 2017, 2019; Yang et al., 2020). Many studies reported an abnormal fecal microbiota in ASD individuals; therefore, the relationship between fecal microbiota and behavioral disorders characteristic of autism can be traced. Frequent GI problems are known to be more common in ASD children than in healthy ones; therefore, nonadaptive behavior correlates with GI problems (Chaidez et al., 2014; Mazefsky et al., 2014; Maenner et al., 2012). Adams et al.
(2011) found a strong correlation of ASD and four ASD subscales (speech, sociability, sensory/cognitive awareness, and physical behavior) with GI severity.

The prevalence rate of GI diseases in ASD children ranges from $9 \%$ to $84 \%$ compared to $9 \%-37 \%$ in children who have no ASD (Wasilewska and Klukowski, 2015). The most frequent GI problems in ASD individuals are chronic constipation, encopresis as a complication of constipation, abdominal pain, also gastroesophageal reflux disease, bloating, disaccharidase deficiency, GI inflammation, and intestinal and nervous system anomalies (Mannion and Leader, 2014).

Children with ASD were demonstrated to suffer from clostridial infection (induced by $C$. difficile, Clostridium bolteae, Clostridium perfringens, and others Clostridium spp.) more frequently that aggravated ASD symptoms (Argou-Cardozo and Zeidán-Chuliá, 2018; Kandeel et al., 2020). Thus, FMT, effective in CDI management, is likely to improve the condition of ASD children.

GI diseases are known to be related to problem behavior in children with ASD (Restrepo et al., 2020), for example, hyperirritability (Bresnahan et al., 2015), disruptive behavior (Ferguson et al., 2019), increase in nonadaptive behavior and social exclusion (Chaidez et al., 2014; Nikolov et al., 2009), and traumatophilia (Marler et al., 2017), as well as sleep problems 


\section{FMT study design}

\section{Recruiting}

Selection of patients by age, absence of acute diseases, ability to drink capsules, etc.

$\downarrow$

\section{Material collection}

- Donor selection

- Collection of fecal material

- Handling or storage of material for oral administration

\section{$\downarrow$}

\section{Research}

- Preparing the patients for research (antibiotic therapy, etc.)

- Treatment by FMT or a placebo

- Observation of treatment results

Figure 1. Study design of FMT in the management of children with ASD.

(Maenner et al., 2012). However, currently, the effect of GI problems on the degree or functional impairments in children with ASD is not adequately investigated. Some researchers have reported that there is no significant effect of GI problems on a mentality level or learning ability (Maenner et al., 2012; Nikolov et al., 2009; Prosperi et al., 2017), as well as the intensity of ASD symptoms (Chandler et al., 2013; Mazefsky et al., 2014; Nikolov et al., 2009; Prosperi et al., 2017), while other sources inform of the significant relationship of GIT disorders with ASD symptoms such as increased sensory sensitivity (Mazurek et al., 2013), repeated behavior (Peeters et al., 2013), and others (Chaidez et al., 2014; Wang et al., 2011).
Currently, ClinicalTrials.gov represents the data on the studies on FMT effect on the condition of children (Adams, 2015, 2019; Michail and Levitt, 2018; Youngster, 2020) and adults (Adams, 2018) with ASD; one of the researches has just been completed (Adams, 2015).

The study design (Fig. 1) includes three main stages: selection of patients; material collection and material preparation for transplants; and treatment.

\section{FMT DELIVERY TECHNIQUES IN THE MANAGEMENT OF CHILDREN WITH ASD}

The techniques chosen when designing clinical studies (Adams, 2015, 2018, 2019; Michail and Levitt, 2018; Youngster, 2020) to deliver fecal microbiota are capsules, colonoscopy, and the oral use of highly purified liquid formulation of fecal microbiota (Hamilton et al., 2012). Fecal material, approximately $50 \mathrm{~g}$, was homogenized in physiological saline, $250 \mathrm{ml}$; the suspension was sieved using a stainless laboratory sieve to remove indigested food and other solid particles. The obtained material was centrifuged at $6,000 \mathrm{~g}$ within 15 minutes and then resuspended up to half of the initial volume in physiological saline. The obtained concentrated suspension of intestinal bacteria was immediately administered to a patient, or glycerol was added (up to $10 \%$ concentration), frozen at $-80^{\circ} \mathrm{C}$, and stored for $1-8$ weeks before usage. Fecal microbiota extract, fresh or frozen, hardly had any odor; it had low viscosity and less intense color compared to the initial material. The present purification method enabled us to administer fecal microbiota orally, the microbiota being mixed with chocolate milk; however, the technique is aesthetically questionable.

Table 2 demonstrates the most frequent FMT delivery techniques in ASD therapy, described and compared in literature.

ASD symptoms and GI symptoms in oral usage of microbiota and enema usage decreased by $47 \%$ and $80 \%$, consequently, compared to the initial level, over the period of a 2-year follow-up (Adams, 2015; Kang et al., 2017). A previous study (Kang et al., 2017) used a 2-week vancomycin treatment followed by a bowel cleanse before FMT. After pretreatment, the authors used a liquid formulation of purified bacteria, with the initial dose given orally or by rectal enema and the maintenance dose given orally with a stomach acid suppressant.

Pathogenic bacteria value in gut microbiota and ASD symptoms significantly decreased in young children given enema and capsules with ultracentrifuge concentrated fecal organisms on a long-lasting basis; however, patients aged 21 showed no marked

Table 2. FMT delivery techniques in ASD therapy.

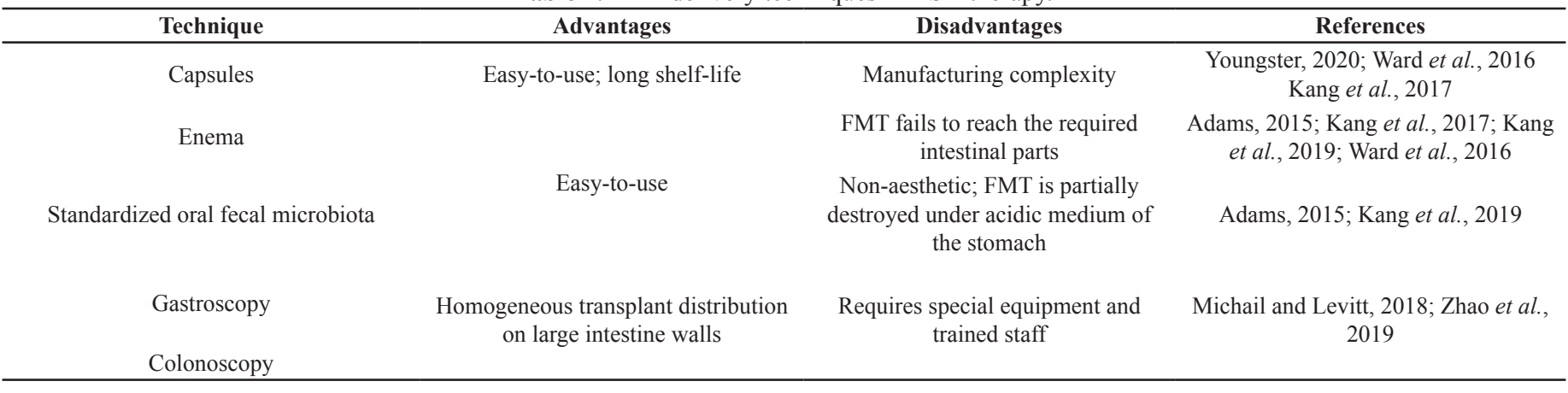


a)

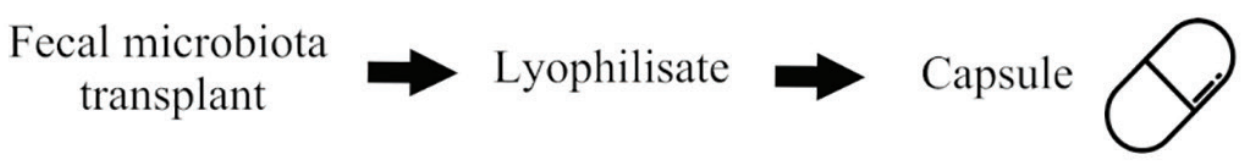

b)

\section{Fecal microbiota $\rightarrow$ Lyophilisate transplant}

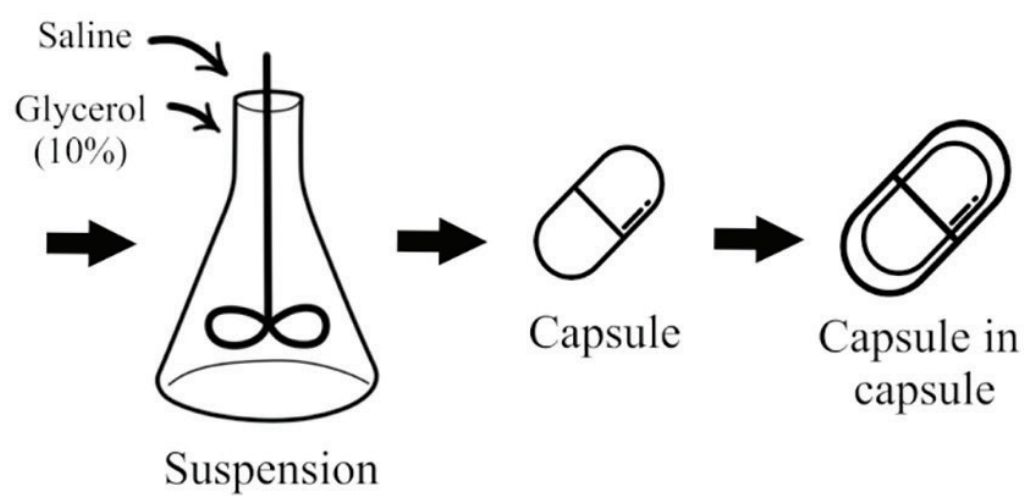

c)
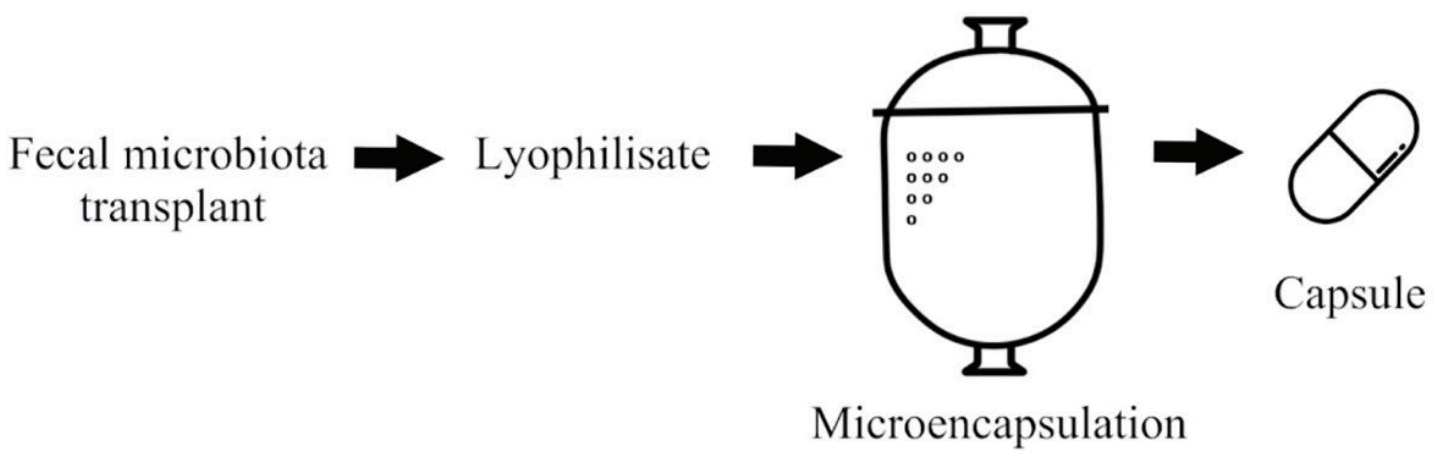

Figure 2. The schemes of possible transplant protection: (a) lyophilisate encapsulated into an enterosoluble capsule; (b) lyophilisate suspension being encapsulated into a double capsule: capsule in capsule; and (c) lyophilisate microencapsulation with the following encapsulation into a gelatin capsule.

improvement (Ward et al., 2016). This study used oral vancomycin pretreatment during 7-10 days without stomach acid suppressants.

FMT administered through gastroscopy and colonoscopy resulted in $10.8 \%$ reduction of ASD symptoms (Zhao et al., 2019).

In terms of treatment before FMT, there has been little research on the use of FMT in ASD to make a detailed analysis; however, similar studies on the treatment of CDI have shown that there is not enough clinical data on the use of pre-FMT bowel lavage, antibiotic, and antacid treatment (Kelly and Tebas, 2018).

Thus, FMT can significantly alleviate patients' conditions suffering from ASD, including children; for this reason, the technique of ASD therapy is being extensively studied recently. Capsules are a promising delivery method in ASD therapy due to the fact that they are easy to use and easy to store.

\section{ENCAPSULATION METHODS FOR FMT}

Canadian researchers, University of Alberta, compared standard colonoscopy with most promising oral capsules. They aimed at developing a less unpleasant technique for patients and significantly improving patients' comfort (Kao et al., 2017). In their study, the authors reported that oral administration can achieve comparable results with the existing rectal techniques, and the cost, at a rough estimate, was thrice as less for oral administration (Kao et al., 2017).

A standard technique of FMT capsule preparation involves obtaining lyophilisate of fecal microbiota followed by its encapsulation into an enteric-coated capsule (Fig. 2a).

However, when preparing oral products, it may be a problem that a microbiota transplant will fail to reach the intestine intact; it is broken in the stomach. To solve such problems, protective mechanisms should be developed for transplants.

Previous studies on the FMT for the RAS treatment have used coadministration of stomach acid suppressants (Kang et al., 2017, 2019). They are also used in the treatment of CDI by the introduction of FMT through the upper GI (Bakken et al., 2011; Kelly and Tebas, 2018). Thus, the use of stomach acid 
suppressants is one way to protect the fecal microbiota from premature destruction in the stomach environment.

Youngster et al. (2016) suggested another interesting protective technique: a donor transplant of lyophilized microbiota was mixed and suspended as concentrated material in sterile physiological saline with $10 \%$ glycerol, being treated under normal conditions and under environmental air. The suspension was twice encapsulated into hypromellose capsules. These capsules were stored at a temperature of $-80^{\circ} \mathrm{C}$ for 6 months pending further usage (Fig. 2b). Previous studies by Youngster et al. (2014a, 2014b), as well as some other authors (Jiang et al., 2017; Youngster et al., 2016), reported the efficacy and safety of oral dosage forms that contained frozen encapsulated fecal microbiota from nonrelative donors in CDI treatment, the total positive effect frequency being $91 \%$ cases, determined as the absence of relapsing diarrhea 8 weeks after 30 capsules administered once or twice (Youngster et al., 2016).

Microencapsulation could be one of the protection mechanisms (Fig. 2c). Microencapsulation is used rather commonly for probiotics and is widely recognized as a kind of protection (Petukhova and Krynicka, 2014). Microencapsulation using gastroresistant material can be applied to accelerate and enhance the positive effect. The microencapsulation concept enables us to separate the main functional ingredient from the environment using a protective covering. The major task of encapsulation technology in pharmacy is a controlled and continuous delivery of cells to the intestine preserving their viability when coming through an acidic gastric medium (Krolevets et al., 2013; Petukhova and Krynicka, 2014).

It is our opinion that additive agents and microencapsulation technologies used for probiotic production can be of help for microbiota transplant microencapsulation.

Biomaterials used for probiotic encapsulation contain natural and synthetic polymers. Due to the low $\mathrm{pH}$ in the gastric medium, these polymers should be acid-resistant to preserve microcapsule structure when coming to the large intestine. In addition, the materials should be biocompatible and easily disintegrate in the bowel. For that purpose, various biomaterials were developed, including alginate (Gombotz and Wee, 2012), Eudragit (Barros et al., 2014), chitosan (Yeung et al., 2016), and pectin (Dafe et al., 2017), designed for encapsulation and effective delivery of probiotic microorganisms existing in the intestinal medium (Dong et al., 2013). The biomaterial should be biocompatible and biodegradable since it is in direct contact with living cells. Alginate is the most common biomaterial used for probiotic encapsulation.

Alginate is often mixed with carob gum and starch to form capsules or gel balls (Ivleva and Kanarskaya, 2014). When mixing the polymers, certain interactions seem to occur. Proportions of each biomaterial before mixing are of primary importance.

Encapsulation technology requires a safe and nonaggressive attitude to cells. To capture and protect probiotics, the following techniques were used: spray drying, lyophilization, and fluid-bed drying (Bakhtin et al., 2009; Gordienko, 2006; Nezhuta et al., 2020). Using the mentioned techniques, probiotics were processed into a concentrated powder form that extends probiotic shelf life.
Spray drying has some disadvantages. For example, probiotic viability can be reduced under the action of high temperatures necessary to water evaporation. The air temperature at the entry is in the range of $100^{\circ} \mathrm{C}-170^{\circ} \mathrm{C}$, and air temperature at the output varies from $45^{\circ} \mathrm{C}$ to $105^{\circ} \mathrm{C}$, in accordance with the literature data (Nazzaro et al., 2012; Sitenkov, 2020). At such temperatures, cells are unlikely to preserve their probiotic activity. Probiotic activity is not the same as probiotic survival. Probiotic activity is the cell's resistance to the GIT medium and ability to adhere to the mucosal surfaces of the intestines. Therefore, the encapsulation technique should not reduce probiotic activity. The use of probiotics with a physical barrier against unfavorable conditions provokes great interest. For this purpose, different methods were introduced for further probiotic protection improvement. The techniques were designed for developing gel balls or capsules made of hydrocolloids by means of extrusion molding or emulsification (Nazzaro et al., 2012). Hydrocolloids are water dispersions of biomaterials (natural or synthetic polymers). Li et al. (2016) used cellulose microgels (CMs) to encapsulate Lactobacillus plantarum. CMs having porous structures were shown to have better bacteria bearer capability. The resistance to acidic medium and survivability can be increased due to the conjugation of bacteria with alginate. In 2017, pectinstarch hydrogels were synthesized to encapsulate $L$. plantarum ATCC:13643 cells by Dafe et al. (2017).

Yeung et al. (2016) developed a microgel "nucleus membrane" containing an alginate nucleus and a chitosan membrane to encapsulate Bifidobacterium longum. It has been shown that viability and resistance of B. longum were significantly improved after encapsulation in aerobic storage and gastric fluid modeling. In 2015, protein-polysaccharide capsules were made for B. adolescentis by Varankovich et al. (2015). The encapsulated bacteria show significant resistance at $37^{\circ} \mathrm{C}$ on a gastric medium model in comparison with free bacteria. Alginate or iota-carrageenan-contained capsules were readily soluble in a modeled intestinal fluid and released $70 \%-79 \%$ bacterial cells within 3 hours. In addition, the use of the lyophilized capsules increased the number of the released living bacterial cells. Another research used alginate and chitosan for layer-by-layer bacteria coating for Bifidobacterium breve (Cook et al., 2013). These multilayered alginate matrices enhanced $B$. breve viability in a low $\mathrm{pH}$ medium and delivered bacterial cells to the bowel, being released there subsequently. Moreover, chitosan-coated alginate microcapsules were developed for Bifidobacterium animalis subsp. lactis PBS075, Lacticaseibacillus rhamnosus PBS070, and L. plantarum PBS067 by D'Orazio et al. (2015). They revealed encapsulated probiotics to exhibit significantly high resistance on a gastric medium model and other unfavorable conditions.

It is essential to preserve the viability of microorganisms as a part of FMT; however, due to the fact that fecal microbiota contains a large number of different bacteria, it is difficult to determine which of them are of great importance in therapy and which have no effect or even reduce the key probiotic function. Despite the fact that FMT usage exhibited positive clinical consequences, currently, it isseparated the activity of microorganisms forming a part of fecal microbiota depending on nosology and individual characteristics of patients. 


\section{CONCLUSION}

Thus, the control of intestinal bacteria by means of FMT encapsulation can become an effective strategy for many diseases, including ASD in children. Future work should focus on investigating FMT action on the ASD symptoms and its dependence on the dosage form. The use of orally administered especially encapsulated FMT will improve access for patients and make the design of placebo-controlled trials more comfortable. A convenient dosage form is very important in the treatment of children with ASD. It is necessary to find optimal dosage form for FMT administration and to continue the study of capsule preparation techniques that can help to protect FMT microorganisms from the acidic medium of the stomach. In this review, it was suggested to obtain lyophilisate of fecal microbiota; after that, lyophilisate is protected using suspending or microencapsulation followed by encapsulating the prepared lyophilisate in an enterosoluble capsule. The present delivery technique of fecal microbiota is characterized by an extended storage life, and it is easy to use.

\section{AUTHOR CONTRIBUTIONS}

All authors made substantial contributions to conception and design, acquisition of data, or analysis and interpretation of data; took part in drafting the article or revising it critically for important intellectual content; agreed to submit to the current journal; gave final approval of the version to be published; and agree to be accountable for all aspects of the work. All the authors are eligible to be an author as per the international committee of medical journal editors (ICMJE) requirements/guidelines.

\section{CONFLICTS OF INTEREST}

The authors report no financial or any other conflicts of interest in this work.

\section{ETHICAL APPROVALS}

Not applicable.

\section{PUBLISHER'S NOTE}

This journal remains neutral with regard to jurisdictional claims in published institutional affiliation.

\section{FUNDING}

This review article was financially funded by State Task Transplantation of intestinal microbiota in children with autism spectrum disorders (ASD) (AAAA-A20-120022590145-1 dated 25.02.2020).

\section{AUTHORS' CONTRIBUTIONS}

All the authors substantially contributed to the conception, compilation of data, checking, and approving the final version of the manuscript.

\section{REFERENCES}

Adams JB, Borody TJ, Kang DW, Khoruts A, Krajmalnik-Brown R, Sadowsky MJ. Microbiota transplant therapy and autism: lessons for the clinic. Expert Rev Gastroenterol Hepatol, 2019; 13(11):1033-7.

Adams JB, Johansen LJ, Powell LD, Quig D, Rubin RA. Gastrointestinal flora and gastrointestinal status in children with autismcomparisons to typical children and correlation with autism severity. BMC Gastroenterol, 2011; 11:22.
Adams JB. Beneficial bacteria treatment for autism (BBT) 2015. [ONLINE]. Available via https://clinicaltrials.gov/ct2/show/ NCT02504554?term $=$ nct02504554\&rank=1 (Accessed 22 May 2021).

Adams JB. Microbiota transfer therapy for adults with autism spectrum disorder (ASD) who have gastrointestinal disorders (MTTASD). 2018. [ONLINE]. Available via https://clinicaltrials.gov/ct2/show/ NCT03408886 (Accessed 22 May 2021).

Adams JB. MTT for children with ASD who have gastrointestinal disorders. 2019. [ONLINE]. Available via https://clinicaltrials.gov/ct2/ show/NCT04182633 (Accessed 22 May 2021).

Adler E, Tabaa A, Kassam Z, Zydek M, Terdiman J, El-Nachef N. Capsule-delivered fecal microbiota transplant is safe and well tolerated in patients with Ulcerative colitis. Dig Dis Sci, 2019; 64(9):2452-4.

Angelberger S, Reinisch W, Makristathis A, Lichtenberger C, Dejaco C, Papay P, Novacek G, Trauner M, Loy A, Bacterial Community Berry D. Temporal dynamics vary among ulcerative colitis patients after fecal microbiota transplantation. Am J Gastroenterol, 2013; 108(10):1620-30.

Argou-Cardozo I, Zeidán-Chuliá F. Clostridium bacteria and autism spectrum conditions: a systematic review and hypothetical contribution of environmental glyphosate levels. Med Sci, 2018; 6(2):29.

Bak SH, Choi HH, Lee J, Kim MH, Lee YH, Kim JS, Cho YS. Fecal microbiota transplantation for refractory Crohn's disease. Intest Res, 2017; 15(2):244-8.

Bakken JS, Borody T, Brandt LJ. Treating Clostridium difficile infection with fecal microbiota transplantation. Clin Gastroenterol Hepatol, 2011; 9(12):1044-9.

Bakhtin IA, Orlova EV, Neschislyayev VA. Universal regimen od sublimation drying of probiotics. Siberian J Clin Exp Med, 2009; 24(4-1):74-5.

Barros JMS, Scherer T, Charalampopoulos D, Khutoryanskiy $\mathrm{VV}$, Edwards AD. A laminated polymer film formulation for enteric delivery of live vaccine and probiotic bacteria. J Pharm Sci, 2014; 103(7):2022-32.

Baunwall SMD, Lee MM, Eriksen MK, Mullish BH, Marchesi JR, Dahlerup JF, Hvas CL. Faecal microbiota transplantation for recurrent Clostridioides difficile infection: an updated systematic review and metaanalysis. EClinicalMed, 2020; 29-30:100642.

Borody TJ, Leis S, Campbell J, Torres M, Nowak A. Fecal microbiota transplantation (FMT) in multiple sclerosis (MS). Am J Gastroenterol, 2011; 106:S352.

Bresnahan M, Hornig M, Schultz, AF, Gunnes N, Hirtz D, Lie KK, Magnus P, Reichborn-Kjennerud T, Roth C, Schjølberg S, Stoltenberg C, Suren P, Susser E, Lipkin WI. Association of maternal report of infant and toddler gastrointestinal symptoms with autism: evidence from a prospective birth cohort. JAMA Psychiatry, 2015; 72(5):466-74.

Cai T, Shi X, Yuan LZ, Tang D, Wang F. Fecal microbiota transplantation in an elderly patient with mental depression. Int Psychogeriatr, 2019; 31(10);1525-6.

Cammarota G, Masucci L, Ianiro G, Bibbò S, Dinoi G, Costamagna G, Sanguinetti M, Gasbarrini A. Randomised clinical trial: faecal microbiota transplantation by colonoscopy versus vancomycin for the treatment of recurrent Clostridium difficile infection. Aliment Pharmacol Ther, 2015; 41:835-43.

Chaidez V, Hansen RL, Hertz-Picciotto I. Gastrointestinal problems in children with autism, developmental delays or typical development. J Autism Dev Disord, 2014; 44(5):1117-27.

Chandler S, Carcani-Rathwell I, Charman T, Pickles A, Loucas T, Meldrum D, Simonoff E, Sullivan P, Baird G. Parent-reported gastrointestinal symptoms in children with autism spectrum disorders. J Autism Dev Disord, 2013; 43(12):2737-47.

Cold F, Browne PD, Günther S, Halkjaer SI, Petersen AM, Al-Gibouri Z, Hansen LH, Christensen AH. Multidonor FMT capsules improve symptoms and decrease fecal calprotectin in ulcerative colitis patients while treated - an open-label pilot study. Scand J Gastroenterol, 2019; 54(3): 289-96. 
Cook MT, Tzortzis G, Khutoryanskiy VV, Charalampopoulos D. Layer-by-layer coating of alginate matrices with chitosan-alginate for the improved survival and targeted delivery of probiotic bacteria after oral administration. J Mater Chem B, 2013; 1(1):52-60.

Cui B, Feng Q, Wang H, Wang M, Peng Z, Li P, Huang G, Liu Z, Wu P, Fan Z, Ji G, Wang X, Wu K, Fan D, Zhang F. Fecal microbiota transplantation through mid-gut for refractory Crohn's disease: safety, feasibility, and efficacy trial results. J Gastroenterol Hepatol, 2015; 30(1):51-8.

Cui B, Li P, Xu L, Peng Z, Xiang J, He Z, Zhang T, Ji G, Nie Y, Wu K, Fan D, Zhang F. Step-up fecal microbiota transplantation (FMT) strategy. Gut Microbes, 2016; 7(4):323-8.

D’Orazio G, Di Gennaro P, Boccarusso M, Presti I, Bizzaro G, Giardina S, Michelotti A, Labra M, La Ferla B. Microencapsulation of new probiotic formulations for gastrointestinal delivery: in vitro study to assess viability and biological properties. Appl Microbiol Biotechnol, 2015; 99(22): 9779-89.

Dafe A, Etemadi H, Dilmaghani A, Mandavinia GR. Investigation of pectin/starch hydrogel as a carrier for oral delivery of probiotic bacteria. Int J Biol Macromol, 2017; 97:536-43.

Dong QY, Chen MY, Xin Y, Qin XY, Cheng Z, Shi LE, Tang ZX. Alginate-based and protein-based materials for probiotics encapsulation: a review. Int J Food Sci Technol, 2013; 48(7):1339-51.

DuPont H. Characterization of fecal microbiome changes after administration of PRIM-DJ2727 in Parkinson's disease patients. 2017. [ONLINE] Available via https://clinicaltrials.gov/ct2/show/NCT03026231 (Accessed 22 May 2021).

El-Salhy M, Hatlebakk JG, Gilja OH, Bråthen Kristoffersen A, Hausken T. Efficacy of faecal microbiota transplantation for patients with irritable bowel syndrome in a randomised, double-blind, placebo-controlled study. Gut, 2020; 69:859-67.

Ferguson BJ, Dovgan K, Takahashi N, Beversdorf DQ. The relationship among gastrointestinal symptoms, problem behaviors, and internalizing symptoms in children and adolescents with autism spectrum disorder. Front Psychiatry, 2019; 10:194.

Gombotz WR, Wee SF. Protein release from alginate matrices. Adv Drug Delivery Rev, 2012; 64:194-205.

Gordienko MG. Modeling and development of continuous technology of spray drying of probiotics: on the example of drying biosuspension of bifidobacteria. Dissertation for the $\mathrm{PhD}$ degree of Technical Sciences, D. Mendeleev University of Chemical Technology, Moscow, Russia, 2006

Groot PF, Frissen MN, Clercq NC, Nieuwdorp M. Fecal microbiota transplantation in metabolic syndrome: history, present and future. Gut Microbes, 2017; 8(3):253-67.

Hamilton MJ, Weingarden AR, Sadowsky MJ, Khoruts A. Standardized frozen preparation for transplantation of fecal microbiota for recurrent Clostridium difficile infection. Am J Gastroenterol, 2012; 107(5):761-7.

Hazan S. Rapid improvement in Alzheimer's disease symptoms following fecal microbiota transplantation: a case report. J Int Med Res, 2020; 48(6):1-6.

Hota SS, Sales V, Tomlinson G, Salpeter MJ, McGeer A, Coburn B, Guttman DS, Low DE, Poutanen SM. Oral vancomycin followed by fecal transplantation versus tapering oral vancomycin treatment for recurrent Clostridium difficile infection: an open-label, randomized controlled trial. Clin Infect Dis, 2017; 64:265-71.

Huang H, Xu H, Luo Q, He J, Li M, Chen H, Tang W, Nie Y, Zhou Y. Fecal microbiota transplantation to treat Parkinson's disease with constipation: a case report. Medicine, 2019; 98(26):e16163.

Hvas CL, Dahl Jørgensen SM, Jørgensen SP, Storgaard M, Lemming L, Hansen MM, Erikstrup C, Dahlerup JF. Randomised clinical trial: faecal microbiota transplantation for recurrent Clostridium difficile infection fresh, or frozen, or lyophilised microbiota from a small pool of healthy donors delivered by colonoscopy. Aliment Pharmacol Therapeut, 2017; 45:899-908
Hvas CL, Dahl Jørgensen SM, Jørgensen SP, Storgaard M, Lemming L, Hansen MM, Erikstrup C, Dahlerup JF. Fecal microbiota transplantation is superior to fidaxomicin for treatment of recurrent Clostridium difficile infection. Gastroenterology, 2019; 156(5): 1324-32.e3.

Ivleva AR, Kanarskaya ZA. Application of polysaccharides as hydrocolloids in food products. Bull Kazan Technol Univers, 2014; 17(14):418-22.

Jiang ZD, Alexander A, Ke S, Valilis EM, Hu S, Li B, DuPont HL. Stability and efficacy of frozen and lyophilized fecal microbiota transplant (FMT) product in a mouse model of Clostridium difficile infection (CDI). Anaerobe, 2017; 48:110-4.

Jiang ZD, Jenq RR, Ajami NJ, Petrosino JF, Alexander AA, Ke S, Iqbal T, DuPont AW, Muldrew K, Shi Y, Peterson C, Do KA, DuPont HL. Safety and preliminary efficacy of orally administered lyophilized fecal microbiota product compared with frozen product given by enema for recurrent Clostridium difficile infection: a randomized clinical trial. PLoS One, 2018; 13:e0205064.

Kandeel WA, Meguid NA, Bjørklund G, Eid EM, Farid M, Mohamed SK, Wakeel KE, Chirumbolo S, Elaseid A, Hammad DY. Impact of Clostridium bacteria in children with autism spectrum disorder and their anthropometric measurements. J Mol Neurosci, 2020; 70(6):897-907.

Kang DW, Adams JB, Coleman D, Pollard EL, Maldonaldo J, McDonough-Means S, Caporaso JG, Krajmalnik-Brown R. Longterm benefit of microbiota transfer therapy on autism symptoms and gut microbiota. Sci Rep, 2019; 9(1):5821.

Kang DW, Adams, JB, Gregory AC, Borody T, Chittick L, Fasano A, Khoruts A, Geis E, Maidonado J, McDonough-Means S, Pollard E, Roux S, Sadowsky MJ, Lipson KS, Sullivan MB, Caporaso JG, Krajmalnik-Brown R. Microbiota transfer therapy alters gut ecosystem and improves gastrointestinal and autism symptoms: an open-label study. Microbiome, 2017; 5(1):10.

Kao D. A prospective, multi-center, randomized trial of fecal microbiota transplantation (FMT) delivered by capsule vs colonoscopy in the management of recurrent Clostridium difficile infection (CDI) 2014. [ONLINE]. Available via https://www.clinicaltrials.gov/ct2/show/ NCT02254811 (Accessed 22 May 2021).

Kao D, Hotte N, Gillevet P, Madsen K. Fecal microbiota transplantation inducing remission in Crohn's colitis and the associated changes in fecal microbial profile. J Clin Gastroenterol, 2014; 48(7):625-8.

Kao D, Roach B, Silva M, Beck P, Rioux K, Kaplan G, Chang H. J, Coward S, Goodman KJ, Xu H, Madsen K, Mason A, Wong GKS, Jovel J, Patterson J, Louie T. Effect of oral capsule- vs colonoscopy-delivered fecal microbiota transplantation on recurrent Clostridium difficile infection: a randomized clinical trial. JAMA, 2017; 318:1985-93.

Kelly BJ, Tebas P. Clinical practice and infrastructure review of fecal microbiota transplantation for Clostridium difficile infection. Chest, 2018; 153(1):266-77.

Kremenchutzky M. Fecal microbial transplantation in relapsing multiple sclerosis patients. 2017. [ONLINE] Available via https:// clinicaltrials.gov/ct2/show/NCT03183869 (Accessed 22 May 2021).

Krolevets AA, Tyrsin YuA, Bykovskaya EE. Application of nano and micro capsulation in pharmaceutical and food industry part 2. Characteristic of incapsulation. Bull Russ Acad Nat Sci, 2013; 13(1):77-84

Landy J, Al-Hassi HO, Mann ER, Peake ST, McLaughlin SD, Ciclitira PJ, Perry-Woodford ZL, Knight SC, Hart AL, Clark SK, Nicholls J. A prospective controlled pilot study of fecal microbiota transplantation for chronic refractory pouchitis. Gastroenterology, 2013; 144(5):S897.

Li W, Luo X, Song R, Zhu Y, Li B, Liu S. Porous cellulose microgel particle: a fascinating host for the encapsulation, protection, and delivery of Lactobacillus plantarum. J Agric Food Chem, 2016; 64(17):3430-6.

Lynch SM, Mu J, Grady JJ, Stevens RG, Devers TJ. Fecal microbiota transplantation for Clostridium difficile infection: a one-center experience. Dig Dis, 2019; 37(6): 467-72. 
Maenner MJ, Arneson CL, Levy SE, Kirby RS, Nicholas JS, Durkin MS. Brief report: association between behavioral features and gastrointestinal problems among children with autism spectrum disorder. J Autism Dev Disord, 2012; 42(7):1520-5.

Mannion A, Leader G. Gastrointestinal symptoms in autism spectrum disorder: a literature review. Rev J Autism Dev Disord, 2014; 1:11-7.

Marler S, Ferguson BJ, Lee EB, Peters B, Williams KC, McDonnell E, Macklin EA, Levitt P, Margolis KG, Beversdorf DQ, Veenstra-VanderWeele J. Association of rigid-compulsive behavior with functional constipation in autism spectrum disorder. J Autism Dev Disord, 2017; 47(6):1673-81.

Mazefsky CA, Schreiber DR, Olino TM, Minshew NJ. The association between emotional and behavioral problems and gastrointestinal symptoms among children with high-functioning autism. Autism, 2014; 18(5):493-501.

Mazurek MO, Vasa RA, Kalb LG, Kanne SM, Rosenberg D, Keefer A, Murray DS, Freedman B, Lowery LA. Anxiety, sensory overresponsivity, and gastrointestinal problems in children with autism spectrum disorders. J Abnorm Child Psychol, 2013; 41(1):165-76.

Michail S, Levitt P. The gut-brain study. 2018. [ONLINE]. Available via https://clinicaltrials.gov/ct2/show/NCT03426826 (Accessed 22 May 2021).

Moayyedi P, Surette MG, Kim PT, Libertucci J, Wolfe M, Onischi C, Armstrong D, Marshall JK, Kassam Z, Reinisch W, Lee CH. Fecal microbiota transplantation induces remission in patients with active ulcerative colitis in a randomized controlled trial. Gastroenterology, 2015; 149(1):102-9.

NazzaroF, OrlandoP, FratianniF, Coppola R. Microencapsulation in food science and biotechnology. Curr Opin Biotechnol, 2012; 23:182-6.

Nezhuta AA, Tokarik EF, Samuylenko AY. Theoretical and practical foundations of the technology of freeze-drying of biological products. KGSHA Publishing House, Kursk, Russia, 2020.

Nikolov RN, Bearss KE, Lettinga J, Erickson C, Rodowski M, Aman MG, McCracken JT, McDougle CJ, Tierney E, Vitiello B, Arnold LE, Scahill L. Gastrointestinal symptoms in a sample of children with pervasive developmental disorders. J Autism Dev Disord, 2009; 39(3):405-13.

Nood E, Vrieze A, Nieuwdorp M, Fuentes S, Zoetendal EG, Vos WM, Visser CE, Kuijper EJ, Bartelsman JF, Tijssen JG, Speelman P, Dijkgraaf MG, Keller JJ. Duodenal infusion of donor feces for recurrent Clostridium difficile. N Engl J Med, 2013; 368:407-15.

Paramsothy S, Kamm MA, Kaakoush NO, Walsh AJ, van den Bogaerde J, Samuel D, Leong RWL, Connor S, Ng W, Paramsothy R, Xuan W, Lin E, Mitchell HM, Borody TJ. Multidonor intensive faecal microbiota transplantation for active ulcerative colitis: a randomised placebo-controlled trial. Lancet, 2017; 389(10075):1218-28.

Peeters B, Noens I, Philips EM, Kuppens S, Benninga MA Autism spectrum disorders in children with functional defecation disorders. J Pediatr, 2013; 163(3):873-8.

Petukhova EV, Krynicka AY. The prospect of using microencapsulated probiotic cultures in the food industry. Bull Kazan Technol Univers, 2014; 17(22):257-60.

Prosperi M, Santocchi E, Balboni G, Narzisi A, Bozza M, Fulceri F, Apicella F, Igliozzi R, Cosenza A, Tancredi R, Calderoni S, Muratori F. Behavioral phenotype of ASD preschoolers with gastrointestinal symptoms or food selectivity. J Autism Dev Disord, 2017; 47(11):3574-88.

Restrepo B, Angkustsiri K, Taylor SL, Rogers SJ, Cabral J, Heath B, Hechtman A, Solomon M, Ashwood P, Amaral DG, Nordahl CW. Developmental-behavioral profiles in children with autism spectrum disorder and co-occurring gastrointestinal symptoms. Autism Res, 2020: 13(10):1778-89.

Shi Y, Dong Y, Huang W, Zhu D, Mao H, Su P. Fecal microbiota transplantation for ulcerative colitis: a systematic review and neta-analysis. PLoS One, 2016; 11(6):e0157259.

Sidhu SS, Nohria S, Sidhu S. Fecal microbiota transplantation in management of hepatic encephalopathy. J Clin Exp Hepatol, 2017; 7:S56.
Sitenkov AY. Creation and research of micro-and nanoscale delivery systems based on polymethacrylate complexes. Dissertation for the $\mathrm{PhD}$ degree of Pharmaceutical Sciences, Kazan State Medical University, Kazan, Russia, 2020

Sood A, Mahajan R, Singh A, Midha V, Mehta V, Narang V, Singh T, Singh Pannu A. Role of faecal microbiota transplantation for maintenance of remission in patients with ulcerative colitis: a pilot study. J Crohns Colitis, 2019; 13(10):1311-7.

Staley C, Kaiser T, Vaughn BP, Graiziger C, Hamilton MJ, Kabage AJ, Khoruts A, Sadowsky MJ. Durable long-term bacterial engraftment following encapsulated fecal microbiota transplantation to treat Clostridium difficile infection. MBio, 2019; 10(4): 01586-619.

Staley C, Kaiser T, Vaughn BP, Graiziger CT, Hamilton MJ, Rehman TU, Song K, Khoruts A, Sadowsky MJ. Predicting recurrence of Clostridium difficile infection following encapsulated fecal microbiota transplantation. Microbiome, 2018; 6(1):166.

Sun J, Xu J, Ling Y, Wang F, Gong T, Yang C, Ye S, Ye K, Wei D, Song Z, Chen D, Liu J. Fecal microbiota transplantation alleviated Alzheimer's disease-like pathogenesis in APP/PS1 transgenic mice. Transl Psychiatry, 2019; 9:189.

Taylor V. Safety and efficacy of fecal microbiota transplantation in a population with bipolar disorder. 2017. [ONLINE] Available via https://clinicaltrials.gov/ct2/show/NCT03279224 (Accessed 22 May 2021).

Varankovich NV, Khan NH, Nickerson MT, Kalmokoff M, Korber DR. Evaluation of pea protein-polysaccharide matrices for encapsulation of acid-sensitive bacteria - 104. Food Res Int, 2015; 70:118-24.

Vendrik KEW, Ooijevaar RE, Jong PRC, Laman JD, Oosten BW, Hilten JJ, Ducarmon QR, Keller JJ, Kuijper EJ, Contarino MF. Fecal microbiota transplantation in neurological disorders. Front Cell Infect Microbiol, 2020; 10:98.

Wang H, Lu Y, Yan Y, Tian S, Zheng D, Leng D, Wang C, Jiao J, Wang Z, Bai Y. Promising treatment for type 2 diabetes: fecal microbiota transplantation reverses insulin resistance and impaired islets. Front Cell Infect Microbiol, 2020; 9:455.

Wang LW, Tancredi DJ, Thomas DW. The prevalence of gastrointestinal problems in children across the United States with autism spectrum disorders from families with multiple affected members. J Dev Behav Pediatr, 2011; 32(5):351-60.

Ward L, O'Grady H, Wu K, Cannon K, Workentine M, Louie T. Combined oral fecal capsules plus fecal enema as treatment of late-onset autism spectrum disorder in children: report of a small case series. Open Forum Infect Dis, 2016; 3:S599.

Wasilewska J, Klukowski M. Gastrointestinal symptoms and autism spectrum disorder: links and risks - a possible new overlap syndrome. Pediatr Health Med Ther, 2015; 6:153-66.

Xu HM, Huang HL, Zhou YL, Zhao HL, Xu J, Shou DW, Liu YD, Zhou YJ, Nie YQ. Fecal microbiota transplantation: a new therapeutic attempt from the gut to the brain. Gastroenterol Res Pract, 2021; 2021:6699268.

Xue LJ, Yang XZ, Tong Q, Shen P, Ma SJ, Wu SN, Zheng JL, Wang HG. Fecal microbiota transplantation therapy for Parkinson's disease: a preliminary study. Medicine, 2020; 99(35):e22035.

Yang J, Fu X, Liao X, Li Y. Effects of gut microbial-based treatments on gut microbiota, behavioral symptoms, and gastrointestinal symptoms in children with autism spectrum disorder: a systematic review. Psychiatry Res, 2020; 293:113471.

Yeung TW, Ucok EF, Tiani KA, McClements DJ, Sela DA. Microencapsulation in alginate and chitosan microgels to enhance viability of Bifidobacterium longum for oral delivery. Front Microbiol, 2016; 7:494.

Youngster I, Mahabamunuge J, Systrom HK, Sauk J, Khalili H, Levin J, Kaplan JL, Hohmann EL. Oral, frozen fecal microbiota transplant (FMT) capsules for recurrent Clostridium difficile infection. BMC Med, 2016; 14(1):134. 
Youngster I, Russell GH, Pindar C, Ziv-Baran T, Sauk J, Hohmann EL. Oral, capsulized, frozen fecal microbiota transplantation for relapsing Clostridium difficile infection. JAMA, 2014a; 312:1772-8.

Youngster I, Sauk J, Pindar C, Wilson RG, Kaplan JL, Smith MB, Alm EJ, Gevers D, Russell GH, Hohmann EL. Fecal microbiota transplant for relapsing Clostridium difficile infection using a frozen inoculum from unrelated donors: a randomized, open-label, controlled pilot study. Clin Infect Dis, 2014b; 58:1515-22.

Youngster I. FMT in children with autism and gastrointestinal symptoms. [ONLINE]. 2020. Available via https://clinicaltrials.gov/ct2/ show/NCT04246398 (Accessed 22 May 2021).

Zhang Z, Mocanu V, Cai C, Dang J, Slater L, Deehan EC, Walter J, Madsen KL. Impact of fecal microbiota transplantation on obesity and metabolic syndrome-a systematic review. Nutrients, 2019; 11(10):2291
Zhao H, Gao X, Xi L, Shi Y. Mo1667 fecal microbiota transplantation for children with autism spectrum disorder. Gastrointest Endosc, 2019; 89:AB512-3.

\section{How to cite this article:}

Malygina D, Volkov A, Zhukova O, Vorobyova O, Panteleev D, Zykova D, Blagonravova A. Review of fecal microbiota transplantation in autistic children and feasible techniques for fecal microbiota transplant delivery. J Appl Pharm Sci, 2022; 12(02):001-009. 